Check for updates

Cite this: Phys. Chem. Chem. Phys., 2021, 23, 9512

Received 6th November 2020, Accepted 9th March 2021

DOI: $10.1039 / \mathrm{d} 0 \mathrm{cp} 05794 \mathrm{k}$

rsc.li/pccp

\section{Cesium and iodine release from fluoride-based molten salt reactor fuel}

\author{
O. Beneš, (D)* E. Capelli, (D) N. Morelová, J.-Y. Colle, A. Tosolin, T. Wiss, B. Cremer \\ and R. J. M. Konings (D)
}

Cesium and iodine, which are formed during a fission process in a nuclear reactor, are considered as major fission products responsible for the environmental burden in case of a nuclear accident. From the safety point of view, it is thus important to understand their release mechanism when overheating of the reactor core occurs. This work presents an experimental investigation of the behaviour of caesium iodide and caesium fluoride in fluoride based molten salt reactor fuel during high temperature events. It has been demonstrated that CsF will be retained in the fuel salt and thus its volatility will be significantly reduced, while Csl will not dissolve in the fluoride-based fuel matrix and will thus remain more volatile. The influence of the presence of Csl and CsF on the melting behaviour of the fuel has been investigated using calorimetry, revealing their negligible effects.

\section{Introduction}

One of the major concerns in case of a nuclear accident is the release of radioactive materials from the fuel into the environment. Volatility is among the main driving forces of such release, which is determined by the temperature and chemical nature of the radioactive material. In practice, two types of radioactive materials exist in the fuel: actinides and formed fission products. In this study we focus on the vaporization behaviour of volatile fission products caesium and iodine in Molten Salt Reactor (MSR) fuel. These two selected fission products are considered as volatiles in solid oxide fuels, ${ }^{1}$ and thus significantly contribute to the source term. ${ }^{2}$ If they stabilize into chemical forms that are less volatile compared to their elemental forms, their volatility will be reduced significantly. Moreover, if the formed chemical species become soluble in the matrix of the molten salt reactor fuel, it is suggested that their volatility will decrease further, by orders of magnitude, proportional to their concentrations. The importance of the chemical form and its influence on the vaporization behaviour are demonstrated in Fig. 1, showing a comparison between the calculated vapour pressures of caesium and iodine in the elemental forms and their halide forms. It is also shown how these vapour pressures compare to the $\mathrm{LiF}$ and $\mathrm{ThF}_{4}$ matrix components (selection of the matrix is discussed further).

To provide insight into the understanding of caesium and iodine vaporization behaviour in the MSR fuel, a series of vapour pressure measurements of actinide containing

European Commission, Joint Research Centre, P.O. Box 2340, 76125 Karlsruhe, Germany sim-fuels were performed using Knudsen Effusion Mass Spectrometry (KEMS) focusing on the most probable stable chemical forms of caesium and iodine, CsF and CsI. The selected fuel matrix was a eutectic composition of the $\mathrm{LiF}-\mathrm{ThF}_{4}$ system (76.5-23.5 mol\%), ${ }^{3}$ a key mixture of the Molten Salt Fast Reactor $(\mathrm{MSFR})^{4}$ studied in the European framework programmes in the last few years. ${ }^{5}$ While caesium bonded with fluorine is well soluble, fluoride based molten fuel mixture studies show ${ }^{6}$ that the solubility of caesium iodide is very limited, which might have a big impact on the volatility of this compound. This phenomenon was discussed in detail in our earlier work ${ }^{7}$ and assessed by phase

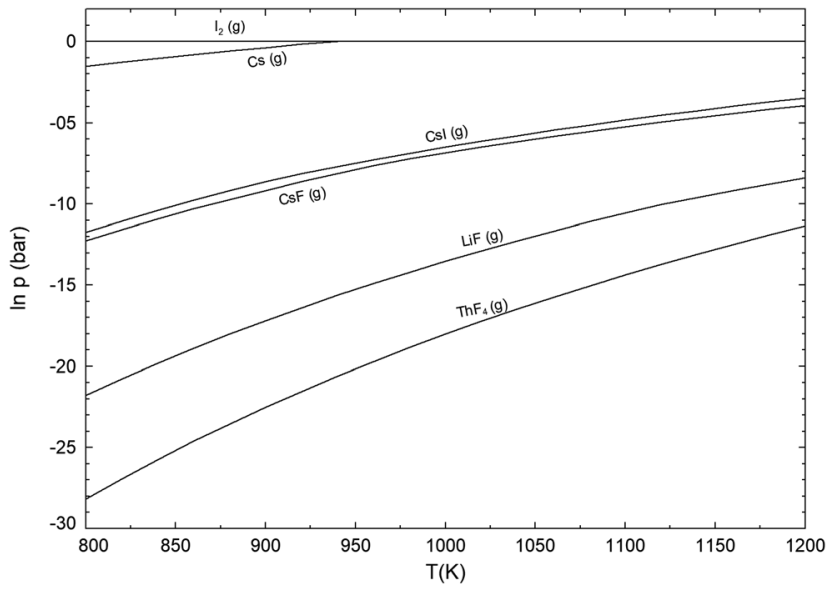

Fig. 1 A comparison of the volatilities of caesium and iodine in their elemental forms with the vapour pressures of $\mathrm{CsF}$ and $\mathrm{Cs}$ l halides and with the $\mathrm{LiF}$ and $\mathrm{ThF}_{4} \mathrm{MSR}$ fuel matrix components. Thermodynamic data source: $\mathrm{Csl}^{8}{ }^{8} \mathrm{CsF}, \mathrm{LiF} \mathrm{ThF}_{4},{ }^{9} \mathrm{Cs}, \mathrm{I}^{10}$ 
equilibrium calculations using a thermodynamic model of the Li-Th-Cs-F-I system.

To investigate the solubility (and thus the retention) of CsI and CsF in the selected MSR fuel, the KEMS measurements were complemented with postanalytical methods using SEM/ EDX and ICP-MS techniques for detection of the remaining traces of caesium and iodine in the fuel after the observed release. In the present study, attention was given to the physical state of the analysed fuel, i.e. to guarantee that the demonstrated volatility of CsF and CsI refers to the molten state of the fuel (under operational conditions of the MSR) and not to the solidified fuel matrix, which is under laboratory conditions always the starting point when synthesising the examined sim-fuel mixtures.

\section{Experimental}

\subsection{Purification and synthesis}

The predominance phase diagram shown in Fig. 2 clearly indicates that the two stable chemical forms of Cs in the presence of iodine and at a fluorine potential typical for a molten salt reactor fuel are CsI and CsF. Both forms strongly depend on the activity of iodine and fluorine, with the latter mainly determined by the fuel composition, i.e. by the $\mathrm{UF}_{4} / \mathrm{UF}_{3}$ ratio. The two dotted lines indicate the fluorine potential window calculated for the $\mathrm{LiF}_{-} \mathrm{ThF}_{4}-\mathrm{UF}_{x}$ (77.5-20.0-2.5 mol\%) composition (fuel option of the MSFR concept) using the thermodynamic database presented in our earlier study. ${ }^{11}$ The upper dotted line corresponds to the redox potential set by the $\mathrm{UF}_{4} / \mathrm{UF}_{3}$ ratio to $100 / 1$ while the lower line corresponds to 10/1 ratio. Both redox potential limits are typical boundary conditions for the MSR. Depending on the activity of fluorine and iodine, CsI and CsF appear to be the stable forms of caesium and iodine fission products in the MSR fuel; thus

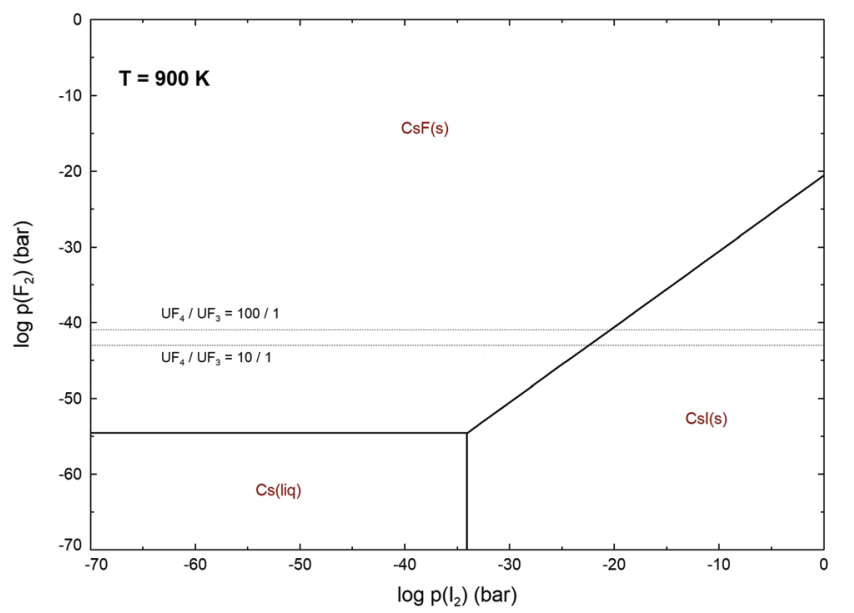

Fig. 2 Predominance phase diagram of caesium with respect to the iodine and fluorine potentials calculated at $900 \mathrm{~K}$. The dotted lines indicate the fluorine potential window calculated for the LiF- $\mathrm{ThF}_{4}-\mathrm{UF}_{x}$ (77.5-20.0-2.5 mol\%) composition with $U_{4} / U_{4}$ ratios of $10 / 1$ and $100 / 1$. The fluorine potential is calculated based on data from ref. 11 and the data on the compounds are taken from ref. 9. the retention capacity of these two compounds in the molten fuel matrix was the subject of this study.

As described further in detail, two different compositions were synthesised and measured to understand various release phenomena of the volatiles from molten salt reactor fuel occurring during high temperature events. The investigated compositions were as follows:

- $1 \mathrm{~mol} \% \mathrm{CsF}$ added to $\mathrm{LiF}^{-\mathrm{ThF}_{4}}$ (76.5-23.5 mol\%)

- $1 \mathrm{~mol} \%$ CsI added to $\mathrm{LiF}^{-\mathrm{ThF}_{4}}$ (76.5-23.5 mol\%)

Selection of $1 \mathrm{~mol} \%$ concentration of CsI and CsF is to some extent slightly overestimated compared to the predicted accumulation during the reactor operation, but (i) such content was needed to detect enough signals for data treatment, and thus to provide reliable measurement, and (ii) it guaranteed to be above the fission yield concentration which is from the safety point of view essential for the demonstration of the retention capacity of the fuel salt.

In addition to the selected compositions, the vapour pressure of the pure CsI compound was measured by KEMS to understand its vaporization behaviour and thus allow proper interpretation of the release mechanism from the MSR fuel. The other three end-members CsF, $\mathrm{LiF}$, and $\mathrm{ThF}_{4}$ were measured using the same technique employed in our earlier studies, ${ }^{12,13}$ and the obtained data were used in this paper for data interpretation.

The synthesis of the salt compositions was done in two major steps. In the first step, the CsI, CsF and LiF endmembers, commercial products obtained from Alfa Aesar (all with the highest available $>99.95 \mathrm{wt} \%$ metallic purity), were purified under a dry argon atmosphere at $300{ }^{\circ} \mathrm{C}$ to release the residual moisture, while $\mathrm{ThF}_{4}$ was synthesised from $\mathrm{ThO}_{2}$ using $\mathrm{HF}$ gas (provided by Linde, $>99.95 \%$ gas purity) at $600{ }^{\circ} \mathrm{C}$ according to the procedure explained in detail by Souček et al. ${ }^{14}$ The purity of the thus obtained $\mathrm{ThF}_{4}$ was checked by X-ray diffraction and by melting temperature. Details of both techniques and their utilizations for the purity check analyses are given in ref. 14, which one can refer to for more details. Only the end-members that showed no indications for impurities on the $\mathrm{X}$-ray diffractograms and for which the reproduced melting points were within $3{ }^{\circ} \mathrm{C}$ of the recommended value were used for analysis. In the second step, the purified end-members were homogenized in appropriate ratios in the solid state using an agate mortar and the thus prepared mixture was used for analysis. As discussed below, some mixtures that were measured using a Knudsen cell were pre-melted prior to the experiment to achieve the best possible homogeneity. This was done in hermetically closed crucibles that were heated well above $(\sim 100 \mathrm{~K})$ the melting temperature of the highest melting end-member. The encapsulation prevented the volatile species from escaping from the formed mixture and after solidification they could be used for vapour pressure measurement.

\subsection{Knudsen effusion mass spectrometry (KEMS)}

The release mechanism of CsI and CsF fission product compounds from the $\mathrm{LiF}-\mathrm{ThF}_{4}$ solvent was studied with a Knudsen effusion cell coupled with a mass spectrometer (KEMS) installed in an alpha-tight and gamma-shielded glove box allowing handling 
of radioactive materials. During the experiment, the sample was placed in the Knudsen cell made of tungsten metal with a very small orifice on the top, which was placed in the high temperature furnace made of tungsten coil and surrounded by a series of thermal shields. Upon heating, the sample evaporated and the escaping gaseous species were driven through a cross-beam electron bombardment where they were ionized and successively analysed in the quadrupole mass spectrometer. The electron energy used in this study was $29.5 \mathrm{eV}$, found to be the optimal value to achieve a high signal to background ratio of the analysed intensity. Normally, the vaporization behaviour using the KEMS device is determined at constant heating rate $10 \mathrm{~K} \mathrm{~min}^{-1}$, but since unique temperature programs had to be applied in the current study to obtain a complete picture of the main findings, the individual temperature programs are described in the respective sub-sections. For more technical details about the KEMS device used in this study one can refer to our previous paper. ${ }^{15}$

The vapour pressure of the molecular species, $p_{i}$, is determined from the measured intensity of the detected signal according to the general equation:

$$
p_{i}=I_{i}^{+} \cdot T \cdot K,
$$

in which $I_{i}^{+}$refers to the measured intensity of the corresponding cation of an evaporated species $i, T$ is the absolute temperature and the $K$ term is obtained by multiplying the calibration factor, $K_{\mathrm{Ag}}$, with a species dependent correction factor, $K_{i} . K_{\mathrm{Ag}}$ is further defined as:

$$
K_{\mathrm{Ag}}=\frac{p_{\mathrm{Ag}}}{I_{\mathrm{Ag}}+\cdot T},
$$

and is fitted to a constant value based on the measurement of silver used as a calibration material, $\mathrm{I}_{\mathrm{Ag}}{ }^{+}$is the measured intensity of silver and $p_{\mathrm{Ag}}$ is the vapour pressure of silver derived from the reference work by Hultgren. ${ }^{16}$ The $K_{i}$ term is dependent on the molar mass of the measured species, $M_{i}$, and its ionization cross section, $\sigma_{i}$, and is defined as:

$$
K_{i}=\frac{\sqrt{M_{i}} \cdot \sigma_{\mathrm{Ag}}}{\sqrt{M_{\mathrm{Ag}}} \cdot \sigma_{i}}
$$

with $\sigma_{\mathrm{Ag}}$ being the cross section of the silver atom used for the calibration. The electron cross sections of atomic or molecular species that are in equilibrium with the condensed sample are defined for the corresponding electron energy and have been calculated using Sigmas software. ${ }^{17}$ By combining the above given equations, the expression for the vapour pressure determination becomes:

$$
p_{i}=\frac{I_{i}^{+} \cdot T \cdot \sqrt{M_{i}} \cdot \sigma_{\mathrm{Ag}} \cdot K_{\mathrm{Ag}}}{\sqrt{M_{\mathrm{Ag}}} \cdot \sigma_{i}} .
$$

As mentioned earlier, the electron energy used to ionize the molecular gaseous species escaping from the Knudsen cell was $29.5 \mathrm{eV}$, high enough not only to ionize the species, but also to dissociate the formed molecular species into smaller cations. This phenomenon must be taken into account and the obtained data must be corrected accordingly for the assessment

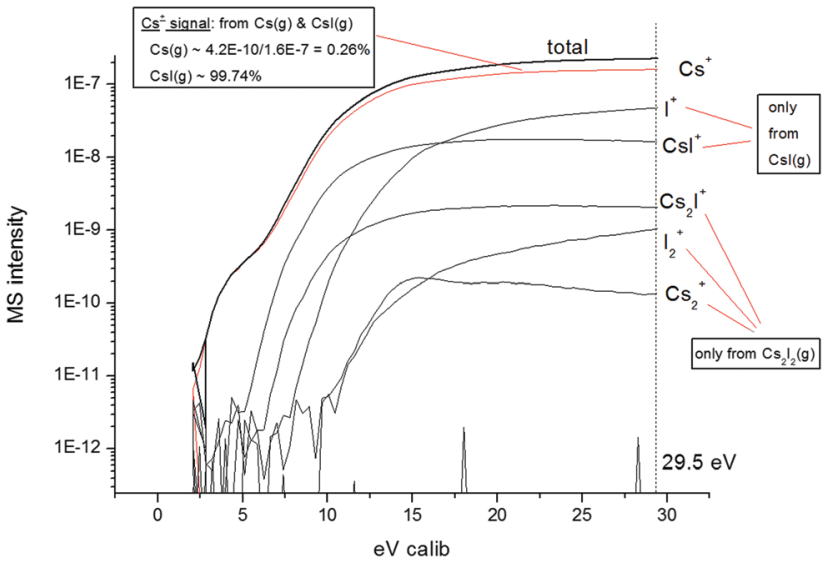

Fig. 3 Appearance potential curve measured for the pure Csl compound.

of final partial vapour pressures. Such correction is done by measuring the appearance potential curves at constant temperature. This can be done either during the measurement of the analysed mixture or in the preceding measurements of the end-members, which were necessary to obtain information about the volatility of all components in their pure states. The appearance potential curves for $\mathrm{LiF}, \mathrm{ThF}_{4}$ and $\mathrm{CsF}$ were measured in our recent studies (ref. 13, 13, and 12, respectively), and since they were measured using the same device keeping the same procedure settings, they were taken into account for the present analysis. The data for the appearance potential of pure CsI were measured in this paper and are presented in Fig. 3.

The figure shows that during the evaporation of pure CsI the detected species at the ionization energy of the measurement (29.5 eV) were $\mathrm{Cs}^{+}, \mathrm{I}^{+}, \mathrm{CsI}^{+}, \mathrm{Cs}_{2} \mathrm{I}^{+}, \mathrm{I}_{2}{ }^{+}$and $\mathrm{Cs}_{2}{ }^{+}$. From further analysis of the appearance potential curve it was found that $99.74 \%$ of the $\mathrm{Cs}^{+}$signal refers to $\operatorname{CsI}(\mathrm{g})$ species, while the remaining $0.26 \%$ refers to $\operatorname{Cs}(\mathrm{g})$ species. Furthermore, the detected $\mathrm{I}^{+}$and $\mathrm{CsI}^{+}$signals refer to the $\mathrm{CsI}(\mathrm{g})$ species only and the $\mathrm{Cs}_{2} \mathrm{I}^{+}, \mathrm{I}_{2}{ }^{+}$and $\mathrm{Cs}_{2}{ }^{+}$signals to the $\mathrm{Cs}_{2} \mathrm{I}_{2}(\mathrm{~g})$ dimer. This speciation was taken into account for the quantification of the partial vapour pressure of CsI.

The correction for the dissociation must be treated individually for every system studied by KEMS and is one of the sources of potential uncertainty of the quantified vapour pressure data. With the temperature and ionization calibration performed regularly on the KEMS device and from the performed analysis presented in this study (taking into account the individual ionization potential corrections and the uncertainty of the cross-section determination), we estimate that all vapour pressure data presented in this paper are subjected to an uncertainty of $\pm 20 \%$.

\subsection{Differential scanning calorimetry (DSC)}

The melting points of the selected sim-fuel mixtures were examined using the differential scanning calorimeter (DSC) detector of a SETARAM multi-detector-high-temperature calorimeter using a B-type sensor with a peak operational temperature of $1600{ }^{\circ} \mathrm{C}$. DSC is a popular thermo-analytical technique in materials science and its principle is based on the measurement of the heat 


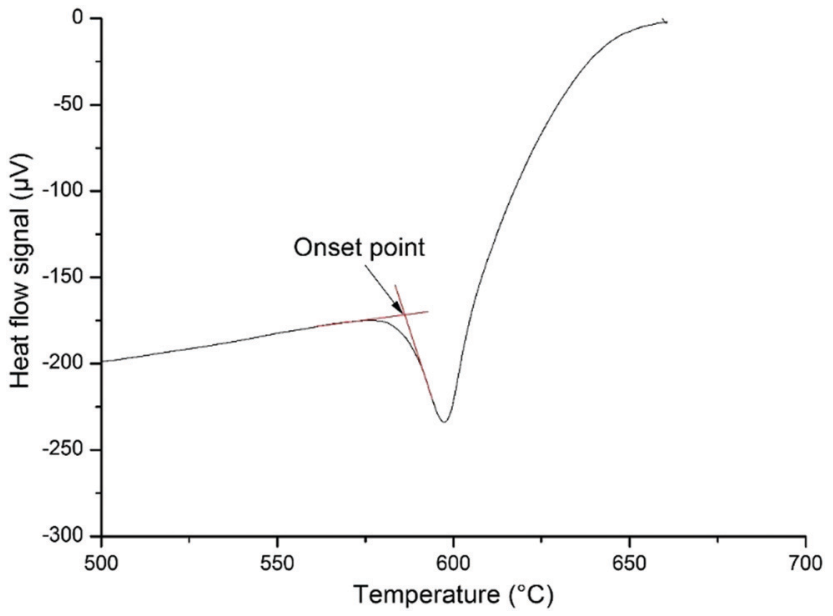

Fig. 4 A DSC output of the measurement of the $\mathrm{LiF}_{-} \mathrm{ThF}_{4}(76.5-23.5 \mathrm{~mol} \%)$ mixture with addition of $1 \mathrm{~mol} \% \mathrm{Csl}$

flow between the reference crucible and the crucible filled with the sample during heating or cooling at a specified rate. During the experiment, the reference crucible was kept empty, while the crucible with the sample was a stainless steel crucible with a tightly screwed lid ensuring hermetic tightness during the measurement. An inner liner of nickel inert material was placed in the crucible to avoid any chemical interaction between molten halide salt and the stainless steel. For more details about this encapsulation technique, one can refer to our earlier study. ${ }^{18}$

As the sample started to melt during the heating, a peak was observed on the DSC curve. The phase transition temperature, in this case the eutectic melting, was identified as the onset of the peak. ${ }^{19}$ A DSC output of the measured $\mathrm{LiF}^{-\mathrm{ThF}_{4}}$ (76.5-23.5 mol\%) mixture with addition of $1 \mathrm{~mol} \% \mathrm{CsI}$ and the onset point determination are shown in Fig. 4.

Before the experiment, a temperature calibration of the instrument was done using a series of reference certified metals with well-defined melting points covering the operational temperature range of the calorimeter from 100 to $1600{ }^{\circ} \mathrm{C}$. The obtained calibration curve was applied to correct the measured temperature as the temperature difference between the position of the sensor and the position of the sample was found due to the kinetics of the heating. As halide salts reveal super-cooling effects during cooling, only the data from the heating cycles were taken into account for melting point determination.

\subsection{Scanning electron microscopy}

The scanning electron microscope (SEM) used in this study was a Philips XL40, in which the column, chamber and high voltage power supply are mounted inside a glove-box allowing for the measurements of radioactive materials. The EDX detector used for the analyses was an EDAX Si detector with a resolution of better than $0.14 \mathrm{keV}$, integrated in a SAMx acquisition and software suite. The quantification was made using a ZAF correction method.

\section{$2.5 \quad$ ICP-MS}

Inductively Coupled Plasma-Mass Spectrometry (ICP-MS) was used to analyse the contents of caesium and/or iodine of the fuel salt mixtures examined by KEMS. A Thermo Fischer Element II instrument was used. The elements were atomised and ionised in high-frequency plasma. After extraction the ions were separated in the mass spectrometer according to their mass-to-charge ratio. The samples analysed by ICP-MS were dissolved in $1 \mathrm{M}$ nitric acid. The measurements were performed according to ISO 17025 standards.

\section{Thermodynamic simulations}

To better interpret the obtained experimental data, a series of thermodynamic calculations were made in this paper. The phase equilibrium determinations were done based on Gibbs energy minimization, according to the so-called CALPHAD method. For all calculations, the commercial FactSage program was used and the input data to determine phase equilibria in

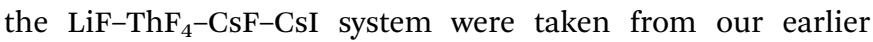
paper, ${ }^{7}$ in which the full thermodynamic assessment of this system was made.

\section{Results}

\subsection{Melting point determination of the mixtures}

As the knowledge of the melting points of both examined mixtures was key to assessing the most appropriate temperature program of the vapour pressure measurement using the KEMS facility, both mixtures were analysed prior to vapour pressure measurement using the DSC technique. The measurement gave insight as well into how much the presence of accumulated fission products affects the melting behaviour of the fuel, a question that is of safety concern.

In total, three samples were measured by DSC: the $\mathrm{LiF}^{-\mathrm{ThF}_{4}}$ (76.5-23.5 mol\%) solvent and their respective CsF- and CsIcontaining mixtures. The DSC experiment consisted of three heating (and cooling) runs at a constant heating rate of $10 \mathrm{~K} \mathrm{~min}^{-1}$. The first run was a homogenization step, whereas the results of the second and third runs were used to determine the melting points.

In the case of the $\mathrm{LiF}^{-\mathrm{ThF}_{4}}(76.5-23.5 \mathrm{~mol} \%)$ solvent mixture only a single DSC peak was observed on the DSC heat flow signal, indicating eutectic (or close to eutectic) melting. In the case of the CsI- and CsF-containing sim-fuel mixtures a very similar peak profile was observed, indicating similar, eutectic type, melting behaviour. The melting peak of the DSC heat flow signal of the CsI-containing mixture is given in Fig. 4. The obtained results of the eutectic melting points measured in this study are summarized in Table 1. It is evident that dissolution of CsF in quantities typical for fission yields and very limited dissolution of CsI (note that CsI remains immiscible as discussed above and in Section 4.3) have almost no effect on the melting point of the MSR fuel. We note here that the melting point of phase-separated CsI was not detected due to the small quantity of the sample. 
Table 1 Measured melting points of the selected MSR sim-fuel mixtures

\begin{tabular}{|c|c|}
\hline MSR fuel mixture & $\begin{array}{l}\text { Measured eutectic } \\
\text { point }(\mathrm{K})\end{array}$ \\
\hline $\mathrm{LiF}-\mathrm{ThF}_{4}(76.5-23.5 \mathrm{~mol} \%)$ & $839.1 \pm 5$ \\
\hline $\mathrm{LiF}-\mathrm{ThF}_{4}(76.5-23.5 \mathrm{~mol} \%)+1 \mathrm{~mol} \% \mathrm{CsF}$ & $838.3 \pm 5$ \\
\hline $\mathrm{LiF}-\mathrm{ThF}_{4}(76.5-23.5 \mathrm{~mol} \%)+1 \mathrm{~mol} \% \mathrm{CsI}$ & $833.3 \pm 5$ \\
\hline
\end{tabular}

\subsection{Release of CsF from $\mathrm{LiF}-\mathrm{ThF}_{4}$}

The first investigated system was $1 \mathrm{~mol} \% \mathrm{CsF}$ added to $\mathrm{LiF}-\mathrm{ThF}_{4}$ (76.5-23.5 mol\%). The mixture was prepared in proportional weights in the solid state and prior to the KEMS experiment homogenized by melting all components together in a hermetically closed crucible which avoided evaporation of CsF or any other components. About $50 \mathrm{mg}$ sample was examined by KEMS and the vapour pressures of all three components were measured as functions of temperature. The temperature program of the measurement consisted of two parts: (i) rapid heating at a rate of $100 \mathrm{~K} \mathrm{~min}^{-1}$ to $900 \mathrm{~K}$, thus with a sufficient margin above the melting point of the mixture; and (ii) successive heating at a constant heating rate of $10 \mathrm{~K} \mathrm{~min}^{-1}$ for the determination of the retention capacity of the molten fuel. The rapid heating program was needed to avoid (or suppress) $\mathrm{CsF}$ evaporation from the solid state as the vapour pressure of pure CsF is significantly higher compared to the $\mathrm{LiF}$ and $\mathrm{ThF}_{4}$ matrix components, as shown in Fig. 1. Reaching the temperature region well above the melting point ensured that the added quantity of CsF fully dissolved in the molten fuel matrix as no indications of pre-release of CsF was found on the mass spectrometry signal during the rapid heating sequence. This observation is in agreement with our previous comprehensive study of the $\mathrm{CsF}^{-\mathrm{ThF}_{4}}$ system. $^{12}$ The small bump observed for the $\operatorname{CsF}(\mathrm{g})$ and $\mathrm{Cs}(\mathrm{g})$ signals slightly above $900 \mathrm{~K}$ evident in Fig. 5 was due to the unstable temperature of the liquid nitrogen cooled cold-trap and related distorted vacuum. A similar bump above $900 \mathrm{~K}$ was also observed on the $\mathrm{ThF}_{4}$ signal.

The quantified vapour pressures of $\mathrm{CsF}, \mathrm{LiF}$ and $\mathrm{ThF}_{4}$ measured in this paper are reported in Fig. 5, and to assess the retention capacity of the MSR fuel towards the CsF fission product form, the data were compared to the vapour pressure of the $\mathrm{LiF}^{-\mathrm{ThF}_{4}}$ (80-20 mol\%) mixture measured earlier by Capelli et al. ${ }^{13}$ calculated pure CsF vapour pressure, ${ }^{9}$ vapour pressure measurements of pure CsF from our earlier study ${ }^{12}$ and experimental data from Eisenstadt et al. ${ }^{20}$

Fig. 5 shows that $\operatorname{CsF}(\mathrm{g})$ and $\mathrm{Cs}(\mathrm{g})$ arising from $\mathrm{CsF}$ dissolved in the salt show even about 10 times lower release compared to $\operatorname{LiF}(\mathrm{g})$, strongly suggesting CsF retention within the fuel salt. Furthermore, the vapour pressure of pure CsF agrees well among all data and is orders of magnitude above the $\operatorname{CsF}(\mathrm{g})$ vapour pressure of the sim-fuel mixture, confirming that the $\mathrm{CsF}$ is dissolved in the solution (otherwise $\mathrm{CsF}(\mathrm{g})$ would be of the same order). The smooth release of $\operatorname{CsF}(\mathrm{g})$ and $\operatorname{Cs}(\mathrm{g})$ species, which starts around $950 \mathrm{~K}$ and follows release of the $\mathrm{LiF}$ and $\mathrm{ThF}_{4}$ matrix components, is another confirmation of CsF dissolution in the sim-fuel melt. The drop of the CsF-species

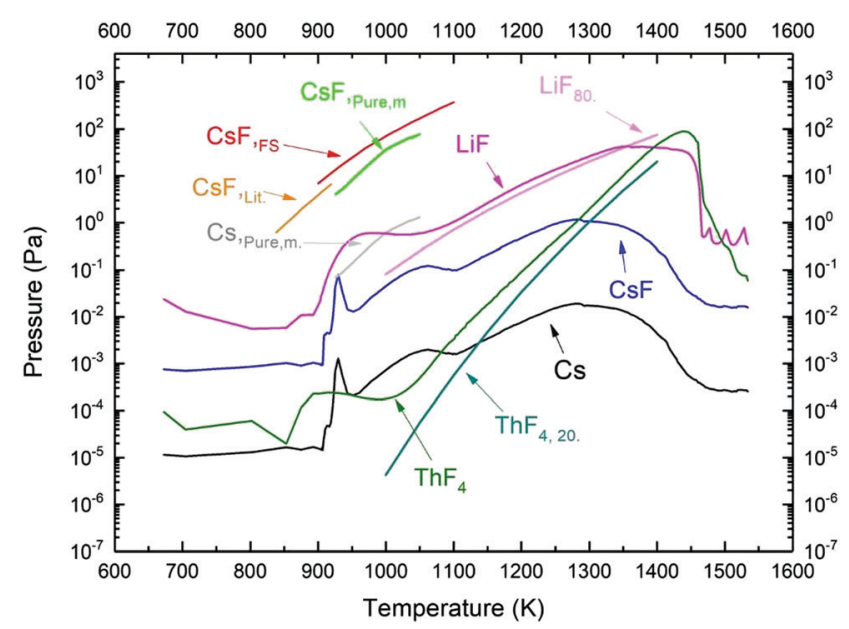

Fig. 5 Output of volatility measurements of 1 mol\% CsF mixed with the $\mathrm{LiF}_{-} \mathrm{ThF}_{4}$ (76.5-23.5 mol\%) matrix (associated signals from the figure: LiF, $\mathrm{CsF}, \mathrm{Cs}, \mathrm{ThF}_{4}$ ) compared with measurements of: (i) the pure CsF compound (associated signals from the figure: $\mathrm{CsF}_{\text {Pure, }}, \mathrm{CS}_{\text {pure, }}$ ) (compared with thermodynamic calculations $\left(\mathrm{CSF}_{\mathrm{FS}}\right)$ and experimental data from the literature $\left.\left(\mathrm{CsF}_{\mathrm{Lit}}\right)^{20}\right)$ and (ii) the $\mathrm{LiF}^{20} \mathrm{ThF}_{4}(80-20 \mathrm{~mol} \%)$ fuel matrix taken from ref. 13 (associated signals from the figure: $\mathrm{LiF}_{80}, \mathrm{ThF}_{4,20}$ ).

related vapour pressure signals is due to the much lower initial quantity of CsF compared to $\mathrm{LiF}$ and $\mathrm{ThF}_{4}$.

The quantification of the $\operatorname{CsF}(\mathrm{g})$ vapour pressure indicates that the volatility of $1 \mathrm{~mol} \%$ of CsF dissolved in the MSR fuel based on the $\mathrm{LiF}^{-\mathrm{ThF}_{4}}$ matrix is about 200-300 times lower compared to CsF in the pure form. The signals of $\mathrm{LiF}(\mathrm{g})$ and $\mathrm{ThF}_{4}(\mathrm{~g})$ are very close to the respective vapour pressures of the $\mathrm{LiF}^{-} \mathrm{ThF}_{4}(80-20 \mathrm{~mol} \%)$ solvent mixture of similar composition measured earlier, ${ }^{13}$ indicating no influence of CsF on the vapour pressure of the mixture. This observation is in line with a rather small initial concentration of CsF.

\subsection{Release of CsI from $\mathrm{LiF}_{-} \mathrm{ThF}_{4}$}

4.3.1 Vapour pressure of CsI. As discussed in the previous sections, the vapour pressures of pure $\mathrm{LiF}, \mathrm{ThF}_{4}$ and CsF were determined using our KEMS technique and these data are essential to precisely interpret the data obtained from the fuel mixtures. As vapour pressure data on CsI measured with our set-up were missing, the gap was filled as part of this study.

The cationic species detected during the measurement were $\mathrm{Cs}^{+}, \mathrm{Cs}^{2+}, \mathrm{CsI}^{+}, \mathrm{I}^{+}, \mathrm{Cs}_{2} \mathrm{I}^{+}$and $\mathrm{CsI}_{2}^{+}$. Unfortunately, we could not detect the $\mathrm{Cs}_{2} \mathrm{I}_{2}^{+}$signal, as the corresponding atomic mass unit of this species was just above the limit of the used mass spectrometer. However, we note that such an instrumental limitation does not significantly affect the main findings of the present study for the following main reasons: (i) the 'missed' $\mathrm{Cs}_{2} \mathrm{I}_{2}{ }^{+}$signal can only be associated with the $\mathrm{Cs}_{2} \mathrm{I}_{2}(\mathrm{~g})$ dimer that has much lower pressure compared to the $\operatorname{CsI}(\mathrm{g})$ monomer; (ii) the retention capacity which is the main concern of the study can be demonstrated by comparison of monomer behaviour only (as mostly done in this study as discussed further throughout Section 4.3); and (iii) at an ionization energy of $29.5 \mathrm{eV}$, significant dissociation of larger molecules 
(as e.g. the $\mathrm{Cs}_{2} \mathrm{I}_{2}(\mathrm{~g})$ dimer) occurs so the $\mathrm{Cs}_{2} \mathrm{I}_{2}{ }^{+}$signal becomes less relevant for the data interpretation. The vapour pressure analysis accounting for the dissociation of CsI and $\mathrm{Cs}_{2} \mathrm{I}_{2}$ gaseous species is provided in Section 2.2, in which the measured appearance potential curve was presented (Fig. 3). The results of the vapour pressure measurements of pure CsI obtained in this paper are shown in Fig. 6 and compared with available data from the literature assessed by Roki et al. ${ }^{8}$ and with complementary thermodynamic calculations performed in this study.

The values of the partial vapour pressure of the $\operatorname{CsI}(\mathrm{g})$ monomer are in a very good agreement with the literature data by Roki et al. as well as with the calculated data. This is, however, not the case for the dimer. The measured partial vapour pressure data of the $\mathrm{Cs}_{2} \mathrm{I}_{2}(\mathrm{~g})$ dimer are somewhat lower compared to the calculated ones, and among the possible reasons might be the detection issue of the $\mathrm{Cs}_{2} \mathrm{I}_{2}{ }^{+}$species which is above the limit of the mass spectrometer as mentioned earlier. On the other hand, at $29.5 \mathrm{eV}$ ionization energy the intensity of such high-mass species is not likely to be very high, as at such high energy the $\mathrm{Cs}_{2} \mathrm{I}_{2}(\mathrm{~g})$ is significantly dissociated. Nevertheless, since the $\operatorname{CsI}(\mathrm{g})$ monomer is the major vapour species of the CsI compound, the measurement of the retention of CsI in the molten salt reactor fuel mainly depends on the correct quantification of this species.

4.3.2 Release of CsI from $\mathrm{LiF}^{-T h F_{4}}$. To study the vaporization behaviour of CsI in the MSR fuel, a mixture of $1 \mathrm{~mol} \% \mathrm{CsI}$ added to $\mathrm{LiF}-\mathrm{ThF}_{4}(76.5-23.5 \mathrm{~mol} \%)$ was prepared in the same manner as in the case of the CsF-containing simfuel. First, all three components were mixed in proportional weights in the solid state, and such a mixture was melted in a hermitically closed crucible to achieve homogeneous distribution of all components. A sample of $50 \mathrm{mg}$ of the thus synthesised salt was placed in a Knudsen cell for vaporization behaviour determination. An identical temperature program for the measurement to that in the case of CsF release was selected, which consisted of two parts: (i) rapid heating above the melting point of the mixture,

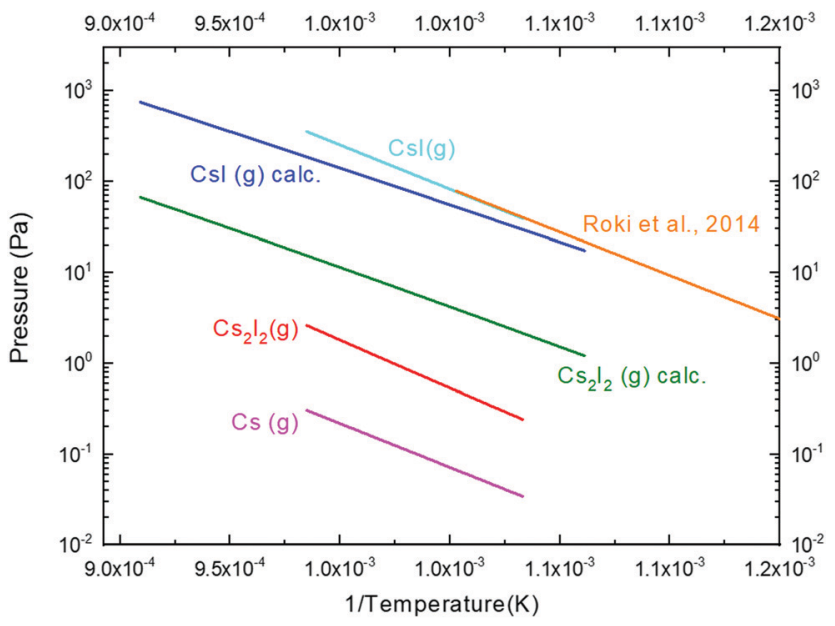

Fig. 6 Measured partial vapour pressures of pure Csl compared with calculated values (denoted as calc.) and review work by Roki et al. ${ }^{8}$

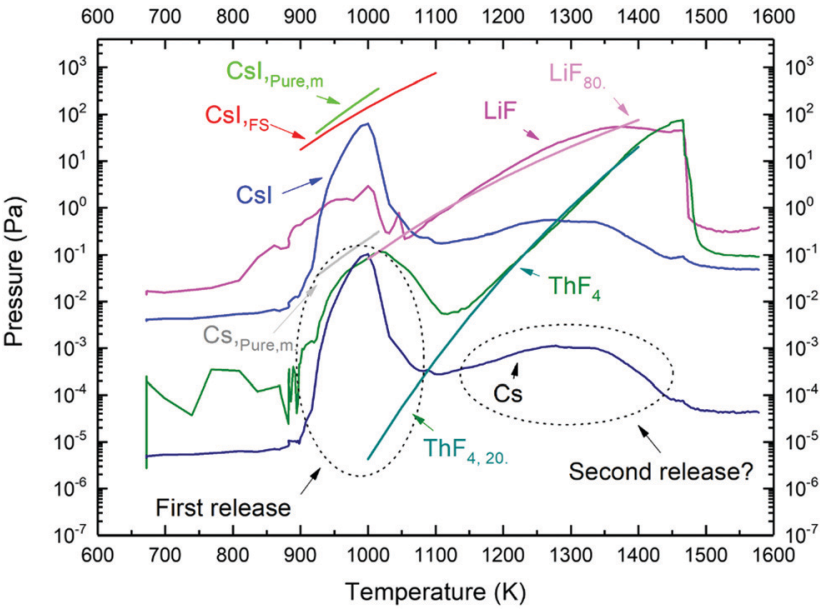

Fig. 7 Output of volatility measurements of 1 mol\% Csl mixed with the $\mathrm{LiF}_{-} \mathrm{ThF}_{4}$ (76.5-23.5 mol\%) matrix (associated signals from the figure: LiF, $\mathrm{Csl}, \mathrm{Cs}, \mathrm{ThF}_{4}$ ) compared with measurements of (i) pure Csl (Csl pure,m) (including thermodynamic calculations $\left(\mathrm{Csl}_{\mathrm{FS}}\right)$ ) and (ii) the $\mathrm{LiF}-\mathrm{ThF}_{4}$ (80-20 mol\%) fuel matrix taken from ref. 13 (associated signals from the figure: $\mathrm{LiF}_{80}, \mathrm{ThF}_{4,20}$ ).

to temperature $900 \mathrm{~K}$ at a rate of $100 \mathrm{~K} \mathrm{~min}^{-1}$; and (ii) successive heating at a constant heating rate of $10 \mathrm{~K} \mathrm{~min}^{-1}$ for the determination of the retention capacity of the molten fuel. The output of the measurement is given in Fig. 7, comparing the obtained results with the vapour pressure data of the $\mathrm{LiF}-\mathrm{ThF}_{4}$ (80-20 mol\%) mixture measured earlier by Capelli et al. ${ }^{13}$ calculated pure CsI vapour pressure and vapour pressure measurements of pure CsI obtained in this paper. We note that for clearer interpretation we show in the figure only the vapour pressure data of $\operatorname{CsI}(\mathrm{g})$ and $\operatorname{Cs}(\mathrm{g})$ and not of the dimer in order to demonstrate the retention capacity.

It is evident from the figure that CsI release was very different from that observed in the case of CsF. A major CsI release was found above $900 \mathrm{~K}$, almost reaching the vapour pressure values of pure CsI. At around $1000 \mathrm{~K}$ a sudden drop was observed, most likely because all CsI evaporated at that point, and once the vaporization of the matrix components increased, the signature of slight second release was found in the vapour pressure curves of CsI. Since the second release was of very low intensity, it was very difficult to judge if that release occurred or if it was a high temperature background effect. For that reason, a separate experiment was performed, quenching the sample after the first major release and subjecting it to chemical analysis, as discussed below. Nevertheless, the presence of the first significant release indicates that no or very little CsI was dissolved in the $\mathrm{LiF}^{-} \mathrm{ThF}_{4}$ fuel matrix. Such observation was confirmed by thermodynamic calculations by Capelli et al., as discussed in the Introduction section. To understand if kinetics might be responsible for such poor dissolution, we performed another experiment using early encapsulation of the sample to allow a longer time to fuse all salt components together before the release measurement.

For such experiments a crucible from silver metal was selected, and once the sample was placed inside, the crucible 
was encapsulated using laser welding. Silver was found to be an ideal candidate, as it is used as a reference material for mass spectrometer calibration, and it was found to be inert to molten fluoride salts (we never observed artefacts on the silver vapour pressure curves which would be due to chemical interaction between the salt and silver). Another criterion fulfilled by silver is the melting point, which is high enough to mix all three components in the molten state, i.e. the melting point of silver $\left(T_{\mathrm{m}}=1235 \mathrm{~K}\right)$ is higher than the eutectic temperature of the mixture, determined by DSC and reported in Table $1\left(T_{\text {eut }}=\right.$ $833.3 \mathrm{~K})$. On the other hand, silver melts at low enough temperature to allow release measurement of the selected salt under the so-called Knudsen conditions, i.e. to distinguish between kinetic burst and vaporization driven by a thermodynamic equilibrium.

The KEMS temperature program for the sample encapsulated in the silver crucible consisted of three steps: (i) fast heating at a rate of $100 \mathrm{~K} \mathrm{~min}^{-1}$ to reach a temperature of $\sim 1200 \mathrm{~K}$, i.e. below the melting point of silver; (ii) dwelling at $1200 \mathrm{~K}$ for $3 \mathrm{~h}$ to allow enough time to homogenize the melt; and (iii) release measurement at a rate of $10 \mathrm{~K} \mathrm{~min}^{-1}$. The early fast heating during the first step had no other meaning than to spare time for the complete experiment as the whole procedure must fit in one working day. Results obtained from the third step corresponding to the release measurement are shown in Fig. 8, highlighting the temperature range close to silver melting. It is evident from the figure that once silver melts at $1235 \mathrm{~K}$, the vaporisation of all three components increases by orders of magnitude, as seen from the sudden increase of the intensity of the detected vapour species. Furthermore, it is shown that both $\mathrm{LiF}(\mathrm{g})$ and $\mathrm{ThF}_{4}(\mathrm{~g})$ gaseous species quickly reach their equilibrium vapour pressure values, and with further temperature increase, their vapour pressures also increase constantly. The case is different for the $\operatorname{CsI}(\mathrm{g})$ signal, which right after the melt of the crucible increases, but almost immediately drops down, clearly indicating that CsI is poorly soluble in the $\mathrm{LiF}^{-\mathrm{ThF}_{4}}$ salt and thus evaporates instantly. A similar conclusion was derived

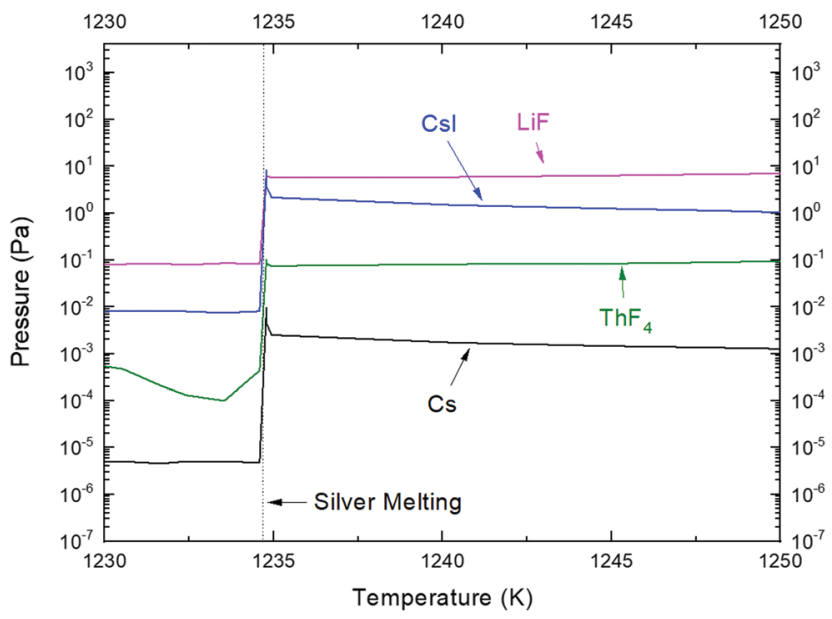

Fig. 8 Vapour pressure measurement of the $1 \mathrm{~mol} \% \mathrm{Csl}$ mixed with the $\mathrm{LiF}-\mathrm{ThF}_{4}(76.5-23.5 \mathrm{~mol} \%)$ matrix in the region of silver crucible melting. in the work of Sekiguchi et $a .^{21}$ studying CsI behaviour in the FLiNaK salt (eutectic composition of the LiF-NaF-KF system).

As in the case of CsF, the presence of CsI did not influence the vaporization behaviour of the $\mathrm{LiF}-\mathrm{ThF}_{4}$ fuel matrix, which is again evident from comparison to the vapour pressure data of the $\mathrm{LiF}^{-\mathrm{ThF}_{4}}(80-20 \mathrm{~mol} \%)$ mixture measured earlier by Capelli et al., ${ }^{13}$ as almost identical behavior was observed, as shown in Fig. 7.

4.3.3 Chemical analysis of the quenched KEMS sample. As mentioned in the previous section, it was evidenced that whereas CsF completely dissolved in the $\mathrm{LiF}_{-} \mathrm{ThF}_{4}$ fuel matrix, CsI was found to be highly insoluble. Furthermore, an indication of a possible second release of CsI from the fuel matrix was observed in the KEMS experiment shown in Fig. 7. Evidence for this could be helpful to assess if at least a partial quantity of CsI dissolved in the fuel or not. Therefore, a duplicate experiment was performed using the KEMS technique, but in that case the analysed sample was quenched from $980 \mathrm{~K}$, right after the initial CsI burst. Successive chemical analysis of the thus quenched sample was made using SEM/EDX and ICP-MS with the aim of determining the presence of the remaining caesium and iodine. The obtained SEM/EDX images of the selected mapped regions of the sample are shown in Fig. 9 and the quantified values for Cs, I and Th (note that $\mathrm{Li}$ is too light for detection by EDX) are summarized in Table 2. The results of the spectral analysis clearly revealed that no iodine was present, but residual traces of caesium were found. In the figure both Cs and I show similar intensities related to the background signal, but in one of the pictures clear brighter white spots are evident in the case of cesium. They are highlighted by red circles.

To confirm the SEM/EDX observation, an independent chemical analysis using ICP-MS was done on the same quenched sample. The results from the ICP-MS analysis confirmed the absence of iodine, but confirmed the presence of caesium. Unfortunately, quantification of the remaining caesium concentration was not possible.

The slight increase of the $\operatorname{CsI}(\mathrm{g})$ and $\operatorname{Cs}(\mathrm{g})$ signals in the high temperature region of the KEMS experiment (as shown in Fig. 7) might be due to the relatively high pressures of other fuel components, which increase the vacuum background levels of the mass spectrometric signal.

4.3.4 Chemical analysis of an encapsulated DSC sample. The KEMS experiment of the CsI-containing sim-fuel sample suggested no solubility (or at least very limited solubility) of CsI in the fluoride based MSR fuel. To support this statement, further investigation was made on the frozen sample that had been measured by DSC earlier, as described in Section 4.1. This sample was subjected to temperatures well above the melting point in a hermetically closed crucible, so evaporation of any of the three components was avoided. This provided an opportunity to identify the distribution of Cs, I and Th within the sample, i.e. to observe if a miscibility gap was formed in the molten state. A similar approach employing mapping of the frozen sample by the SEM/EDX technique was used.

SEM images of the sample with selected magnifications are shown in Fig. 10. In the SEM images on the right $(5000 \times)$ the 

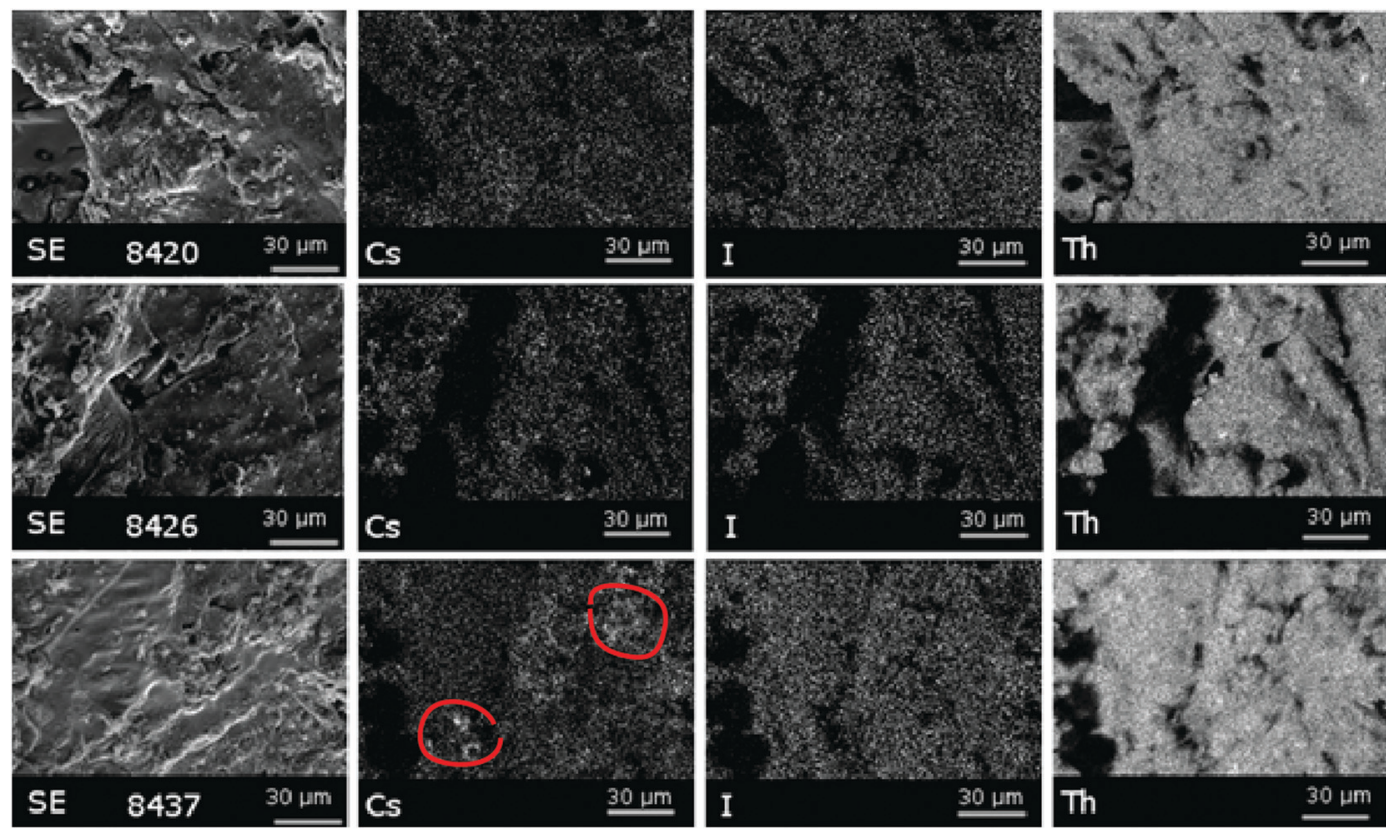

Fig. 9 Selected SEM/EDX images of the eutectic LiF-ThF 4 with $1 \mathrm{~mol} \%$ of Csl sample measured by KEMS up to $980 \mathrm{~K}$ and subsequently quenched to room temperature. The picture shows observations from three different sample locations (horizontal alignment); SE stands for secondary images; Cs, I and Th stand for images showing the visual intensities of the respective atoms. All images are obtained with $800 \times$ magnification.

Table 2 SEM/EDX quantification of the Th, I and Cs contents in the mapped regions of the $\mathrm{LiF}-\mathrm{ThF}_{4}$ fuel matrix with $1 \mathrm{~mol} \%$ of $\mathrm{Csl}$ measured by KEMS up to $980 \mathrm{~K}$ and subsequently quenched to room temperature. The IDs in the table refer to the same IDs in Fig. 9

\begin{tabular}{llclccc}
\hline ID & Area & Mag. & Element & Int. & Wt $\%$ & At\% \\
\hline 8420 & Centre & \multirow{2}{*}{$800 \times$} & I & 0 & 0 & 0 \\
& & & Cs & 2.9 & 1.7 & 0.7 \\
& & Th & 228.1 & 68.41 & 16.12 \\
8426 & \multirow{2}{*}{ Border right } & \multirow{2}{*}{$800 \times$} & I & 0 & 0 & 0 \\
& & & Cs & 1.1 & 1.07 & 0.47 \\
& & & Th & 151.2 & 71.45 & 17.96 \\
8437 & \multirow{2}{*}{ Top right } & \multirow{2}{*}{$800 \times$} & I & 0 & 0 & 0 \\
& & & Cs & 4.5 & 2.21 & 1.06 \\
& & & Th & 293.3 & 73.2 & 20.15 \\
& & & & & & \\
\hline
\end{tabular}

particles of $\mathrm{LiF} \mathrm{ThF}_{4}$ and CsI are clearly visible. Chemical analysis of the particles was done by coupling SEM with EDX techniques, as shown in Fig. 11. The images in the first row of the figure correspond to a magnification of $500 \times$, while those in the bottom row correspond to a magnification of $800 \times$. Unfortunately, it was not possible to detect $\mathrm{LiF}$ because both $\mathrm{Li}$ and $\mathrm{F}$ are too light and not suitable for EDX detection. However, there is strong evidence, e.g. the binary phase diagram, ${ }^{3}$ to assume that in the molten state LiF is homogeneously mixed with $\mathrm{ThF}_{4}$. The EDX mapping shown in Fig. 11 clearly indicates that CsI is not mixed with the rest of the sample, as the mapping identifying Th (right picture of Fig. 11) is bright exactly where the mapping of Cs and I is dark.

The quantitative chemical analysis of the mapped regions shown in Fig. 11 is given in Table 3. The two zones analysed are in good mutual agreement and both show significant quantities of I and Cs with close to 1:1 molar ratios, while the concentration of Th is very low.

\section{Discussion}

In the present study we focused on two probable chemical forms of two highly relevant fission products, Cs and I, and their vaporization behavior from molten salt reactor fuel. From the obtained results it was clearly demonstrated that while CsF is fully soluble in the fluoride based MSR fuel, the contrary is true for CsI. The latter conclusion was not only confirmed by the performed KEMS analysis, but also by SEM/EDX chemical mapping of the quenched sample. In terms of limited CsI solubility, this study confirmed earlier predictions based on thermodynamic equilibrium calculations done by Capelli et al.

Putting the thermodynamic data into context with the obtained experimental results, a strong correlation was obtained. In the case of $1 \mathrm{~mol} \%$ of $\mathrm{CsF}$ added to the $\mathrm{LiF}-\mathrm{ThF}_{4}$ (76.5-23.5 mol\%) fuel, the calculated vapour pressure of CsF ranges from very low $2.6 \times 10^{-4} \mathrm{~Pa}$ at $900 \mathrm{~K}$ to $0.2 \mathrm{~Pa}$ at $1200 \mathrm{~K}$, in excellent agreement with our experimental findings, as e.g. depicted in Fig. 5. Furthermore, the $\mathrm{LiF}-\mathrm{ThF}_{4}$ phase diagram with a fixed concentration of CsF of $1 \mathrm{~mol} \%$ was calculated, and as shown in Fig. 12a, it confirms the complete solubility of CsF in the $\mathrm{LiF}-\mathrm{ThF}_{4}$ solvent as no miscibility gap is found in the liquid region. A similar phase diagram was calculated for addition of $1 \mathrm{~mol} \%$ of CsI, and the results are given in Fig. 12b. In this case, a clear large immiscible region is found in the liquid solution, which explains the limited solubility of CsI in the $\mathrm{LiF}^{-\mathrm{ThF}_{4}}$ based solvent resulting in higher volatility. 

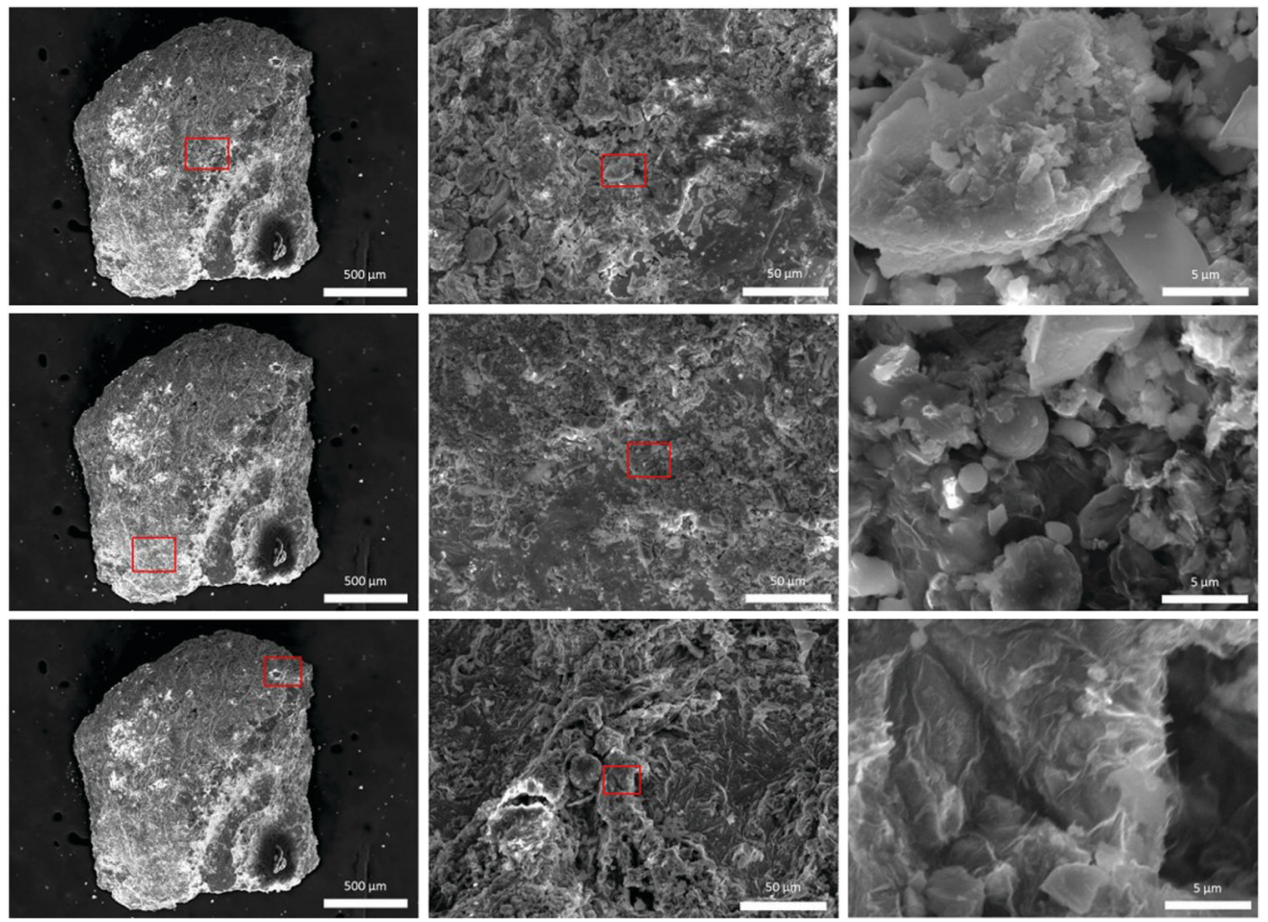

Fig. 10 SEM images of the LiF-ThF 4 eutectic with 1 mol\% of Csl after melting in a DSC crucible. Each horizontal series corresponds to a different sample location; left figures correspond to $50 \times$ magnification; middle figures to $500 \times$ magnification and right figures to $5000 \times$ magnification.
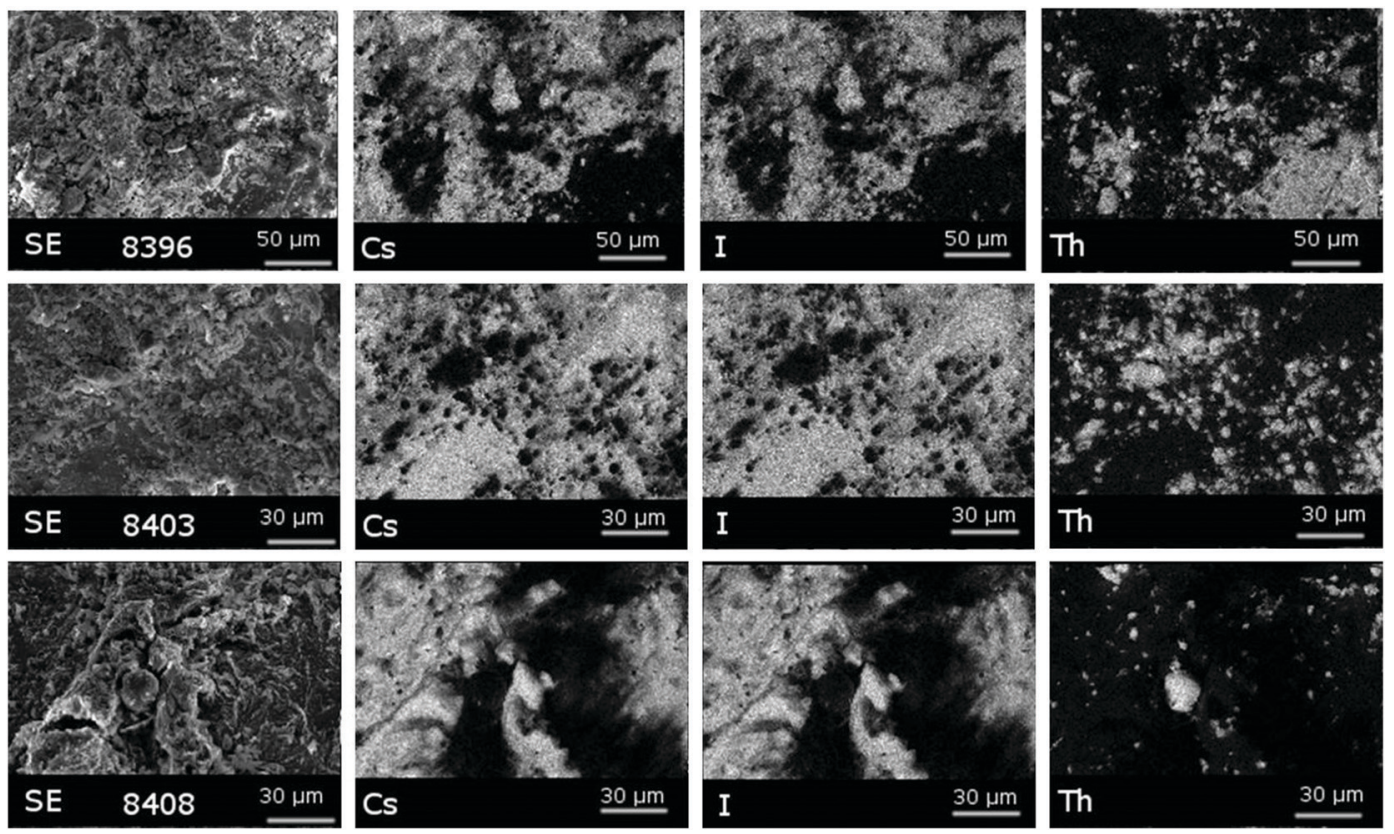

Fig. 11 Mapping of the $\mathrm{LiF}-\mathrm{ThF}_{4}$ eutectic with $1 \mathrm{~mol} \%$ of $\mathrm{Csl}$ after melting in a DSC crucible using the EDX technique. The picture shows observations from two different sample locations (horizontal alignment); SE stands for secondary images; and Cs, I and Th stand for images showing the visual intensities of the respective atoms. The upper series correspond to $500 \times$ magnification, while the lower series correspond to $800 \times$ magnification.

The calculated vapour pressure of $\operatorname{CsI}(\mathrm{g})$ from the $\mathrm{LiF}^{-\mathrm{ThF}_{4}}$ (76.5-23.5 mol\%) fuel solvent was found to be $4.5 \mathrm{~Pa}$ at $900 \mathrm{~K}$, increasing to $560 \mathrm{~Pa}$ at $1200 \mathrm{~K}$. In comparison, the vapour pressure of pure CsI was $16 \mathrm{~Pa}$ at $900 \mathrm{~K}$, increasing to $3000 \mathrm{~Pa}$ at $1200 \mathrm{~K}$. A comparison of these two calculated values is very well correlated with our experimental observations using the KEMS technique (Section 4.3.1), which suggested only a small drop of CsI vapour pressure from the fuel mixture compared to 
Table 3 Quantitative analysis of the mapped regions by SEM/EDX of the $\mathrm{LiF}-\mathrm{ThF}_{4}$ eutectic with 1 mol\% of Csl after melting in a DSC crucible

\begin{tabular}{llllll}
\hline ID & Mag. & Element & Intensity & Weight\% & Atomic\% \\
\hline 8396 & $500 \times$ & I & 206.2 & 38.8 & 27.28 \\
& & Cs & 175.6 & 35.44 & 23.79 \\
8403 & \multirow{2}{*}{$800 \times$} & Th & 84.8 & 12.81 & 4.93 \\
& & I & 228.5 & 37.31 & 25.32 \\
& & Cs & 193.9 & 34.02 & 22.04 \\
& & Th & 116.6 & 15.05 & 5.59 \\
\hline
\end{tabular}

pure CsI. From this, we can conclude that although CsI has very limited solubility in the $\mathrm{LiF}-\mathrm{ThF}_{4}$ fuel, a small effect on vapour pressure is evident, but much lower compared to the CsF.

Furthermore, the results of the current study strongly indicate a partial exchange reaction of CsI into another, most likely soluble form, which is of fluoride based chemical nature. This observation was confirmed by chemical analysis of the quenched CsI-LiF-ThF sample performed using SEM/EDX, complemented with the ICP-MS method. Both techniques showed the obvious presence of cesium, whereas no traces of iodine were found. Since the simple possible exchange reactions such as

$$
\mathrm{CsI}+\mathrm{LiF} \rightarrow \mathrm{LiI}+\mathrm{CsF}
$$

and

$$
4 \mathrm{CsI}+\mathrm{ThF}_{4} \rightarrow \mathrm{ThI}_{4}+4 \mathrm{CsF}
$$

are not thermodynamically favorable as the Gibbs energies of the pair exchange reactions are positive, we performed a series of thermodynamic calculations using the JRCMSD thermodynamic database, and particularly the full thermodynamic description of the Li-Cs-Th-F-I system, ${ }^{7,11}$ which does not only take into account Gibbs energy relations between isolated species, but also the activities of possible end-members that can stabilize in the molten state. With this database, starting from the CsI-LiF$\mathrm{ThF}_{4}$ (1.0-75.7-23.3 mol\%) composition (corresponding exactly to the sim-fuel studied in this paper), the following observation was found for $980 \mathrm{~K}$, which is the quenching temperature used in this study:
- A miscibility gap in the liquid solution was found at $980 \mathrm{~K}$ (as shown in Fig. 12b).

- The calculated compositions of two liquids in equilibrium at $980 \mathrm{~K}$ and their total quantities are (all numbers are in $\mathrm{mol} \%)$ :

$\mathrm{L}_{1}$ (94.1 mol\%): $\operatorname{LiF}$ (76.1); $\mathrm{ThF}_{4}$ (23.3); CsF (0.35); CsI (0.0007); LiI (0.16); $\mathrm{ThI}_{4}(0.05)$

$\mathrm{L}_{2}$ (5.9 mol\%): $\mathrm{LiF}$ (62.2); $\mathrm{ThF}_{4}$ (20.6); CsF (10.4); CsI (0.75); LiI (4.5); $\mathrm{ThI}_{4}$ (1.5)

- The values given in the bullet point above confirmed the partial formation of $\mathrm{Li}$ - and Th-based iodides in the molten fluoride environment, as well as the formation of CsF, which was further dissolved in the fuel (was retained).

- It was confirmed that a very limited solubility of CsI is achieved in the $\mathrm{LiF}-\mathrm{ThF}_{4}$ solvent.

- The vapour pressure at $980 \mathrm{~K}$ was dominated by $\operatorname{CsI}(\mathrm{g})$ (25 Pa), with $\mathrm{LiI}(\mathrm{g})$ (2.8 Pa) as the second largest contributor. We accentuate that both volatile species carried iodine, whereas only one contained cesium.

All the above summarized conclusions explain that there is indeed a partial exchange reaction possible between CsI and fluoride based solvent and this very well explains why no iodine was found in the quenched sample, while traces of Cs (most likely stabilized as CsF) remained dissolved.

Assuming that the source term of fission products would be mainly driven by their volatilities, one can assess the source term reduction from the results obtained in this study. For simplification purposes, the reduction of the source term of caesium and iodine is graphically represented in Fig. 13 by plotting the calculated vapour pressures of Cs- and I-related species on a logarithmic scale with reference to the elemental forms. The green arrows indicate the importance of two factors: (i) the chemical form in which the fission product will stabilize, and (ii) whether that chemical form is soluble in the fuel matrix or not. The graph assumes nominal concentrations of Cs and I of $1 \mathrm{~mol} \%$ and summarizes the main findings of this study, which are discussed further in detail.

For the discussion it is important to realise that the average fission yield of cesium in nuclear fuel is about $10 \times$ higher
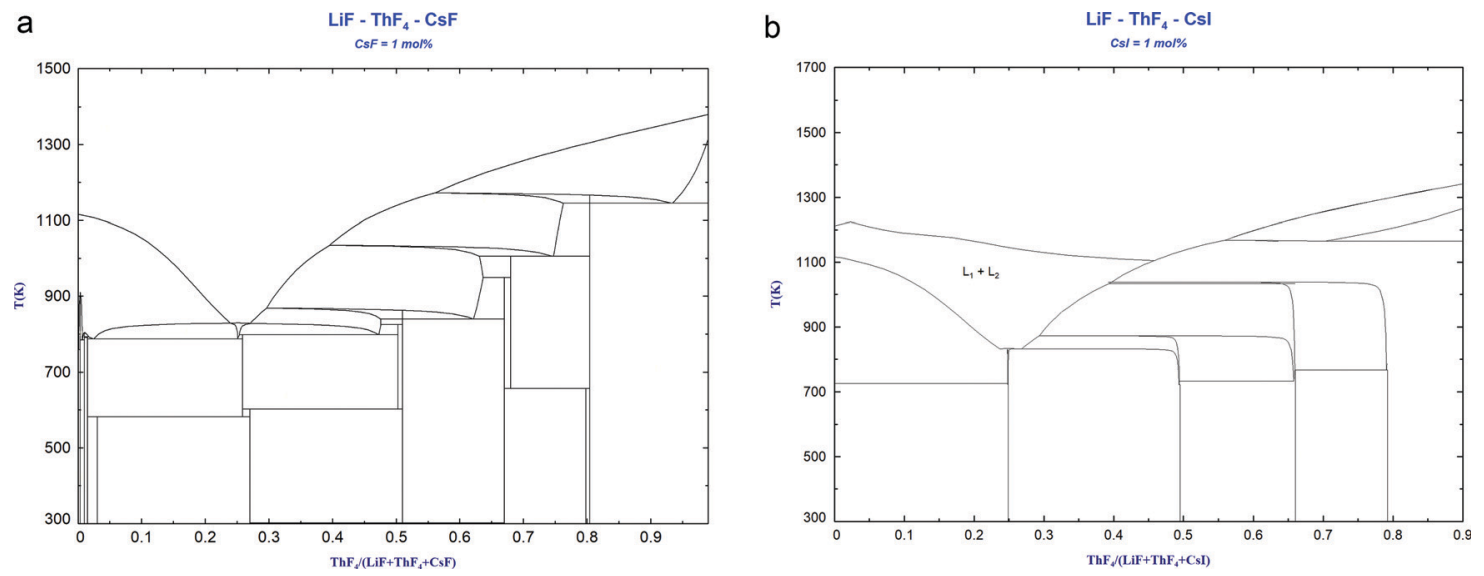

Fig. 12 (a) A calculated $\mathrm{LiF}_{-} \mathrm{ThF}_{4}$ phase diagram with a fixed concentration of $\mathrm{CsF}$ of 1 mol\%. (b) A calculated LiF-ThF 4 phase diagram with a fixed concentration of $\mathrm{Csl}$ of $1 \mathrm{~mol} \%$. 


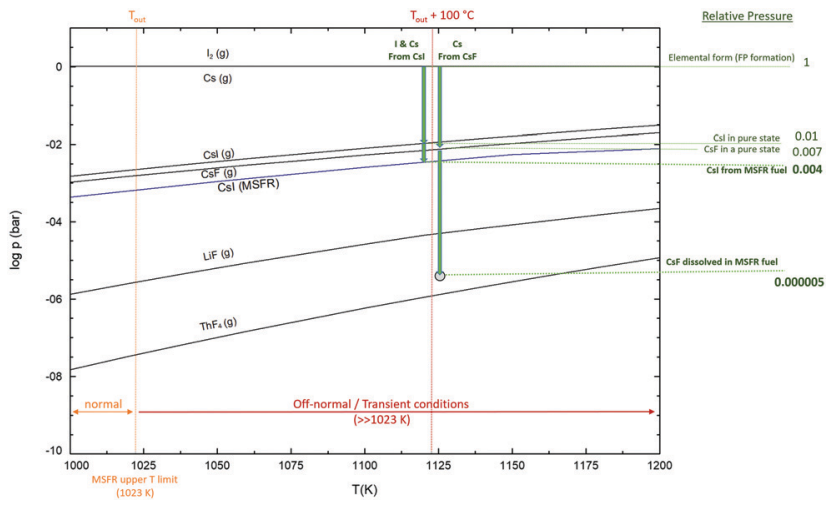

Fig. 13 Graphical assessment of the release potential (pressure) of iodine and caesium in their nominal concentrations of 1 mol\% from LiF-ThF 4 MSR fuel solvent at $1123 \mathrm{~K}$ based on the volatility of Csl and CsF components. The dot in the figure corresponds to the experimental value determined by the KEMS experiment.

compared to iodine. Whether cesium will preferentially react with iodine to form iodide or with fluorine to form fluoride will depend on the actual values of the fluorine and iodine potentials, as already demonstrated in Fig. 2. The chemical form in which iodine stabilized was extensively studied during the Molten Salt Reactor Experiment program at Oak Ridge National Laboratory, ${ }^{22}$ concluding that most of the iodine would become iodide $\left(\mathrm{I}^{-}\right)$and the remaining iodine, which is a daughter product of xenon gas, would be stripped away through a sparging system (e.g. online helium bubbling) and treated as waste.

Now, assuming the worst case, i.e. the thermodynamic preference in the Cs-I-F system will be given to the formation of poorly soluble CsI rather than CsF, the resulting ratio that would stabilize in the fluoride based MSR fuel would be 1 part of CsI and 9 parts of CsF (neglecting the iodine stripped away by online clean-up). Starting from the elemental forms of Cs and I, which are formed upon fission of actinides and following the green vertical arrow, which represents the source term at a selected temperature $100{ }^{\circ} \mathrm{C}$ higher than the upper operating temperature limit of the MSFR, ${ }^{4}$ the figure highlights how the chemistry influences the release based on volatility. The figure clearly shows that just the stabilization of iodine in the form of iodides at $1123 \mathrm{~K}$ results in $100 \times$ lower release potential compared to the elemental form. A further decrease of the iodine pressure is due to the partial solubility of iodides in fluoride salt media, but as shown in this paper, the solubility is very low and therefore the effect on the vaporization behavior is very low too. According to the results of this study, the final pressure of iodine compared to the elemental form will be $200-300 \times$ lower. The same relative drop is expected for cesium arising from CsI.

Since cesium most likely stabilizes as CsF, the source term reduction will be much bigger due to its complete solubility in the fluoride based MSR fuel. The decrease of the volatility indicated in Fig. 13 is again represented by two green arrows, with the first one showing the drop due to chemical stabilization in the cesium fluoride form, while the second and larger one is due to high solubility, and related retention in the fuel. The source term of Cs arising from CsF was assessed based on the present study - neglecting kinetic effects - to be $2 \times 10^{5}$ times lower compared to the volatility of its elemental form. It is important to note that such a value corresponds to simulated initial $1 \mathrm{~mol} \%$ of CsF, but the value corresponding to real reactor conditions might be even lower, while in case the volatility is given by the total amount dissolved in the fuel, it is at the same time proportional to concentration.

\section{Conclusions}

Several key conclusions related to the understanding of the retention capacity of fluoride-based molten salt reactor fuel with respect to fission products were drawn based on the results of this paper. Firstly, it was demonstrated that the chemistry of the fission products plays a key role in determining their volatility during high temperature events. It is very likely that due to the molten state of the fuel and the thus related high mobility of the cations, the thermodynamically stable form will be quickly bonded in the MSR fuel, as opposed to solid oxide fuels, in which some fission products are non-bonded and the retention is due to the fact that the solid matrix inhibits cation (fission product) migration within the fuel pellet. Secondly, the study clearly showed that if the fission product cesium was stabilized in the fluoride fuel in the chemical form of CsF, it would remain dissolved in the composition range typical for an average fission product yield. Consequently, the volatility of the thus dissolved CsF would be significantly lower compared to pure CsF and would considerably contribute to lower cesium release during a high temperature event. To quantify, the present study showed that $1 \mathrm{~mol} \%$ of dissolved CsF has about 200-300 times lower volatility than CsF in the pure state (i.e. not part of the matrix). On the other hand, the fission product iodine is less well bonded in the MSR salt due to the very limited solubility of iodides in the fuel matrix. If it associates with cesium, CsI will form, and if the solubility limit (still to be determined experimentally) is exceeded, its volatility will be close to that of pure CsI. Hence, the release of iodine will not be affected to the same extent as in the case of CsF; however, the fact that the formed iodine stabilizes as iodide (most likely catching an alkali metal) and thus does not remain in the much more volatile elemental form reduces the iodine source term considerably. Furthermore, fission yield calculations suggested that about 10 times more cesium was formed than iodine. This means that even if all (or almost all) iodine would preferentially react with cesium to form CsI, which remained in large quantities undissolved, the remaining cesium (9 parts from 10) would most likely stabilize in the form of dissolved CsF in the MSR fuel (being retained in the MSR fuel). Furthermore, elemental analysis of the quenched samples of the KEMS experiment evidenced that exchange reaction between CsI and the fluoride fuel matrix took place as no iodine was found in the quenched sample, whereas cesium was observed. The interpretation of these results clearly demonstrated the importance of the 
correlation between experimental studies and e.g. thermodynamic simulations, as it leads to better understanding of the fundamentals of the fuel behaviour. Finally, a complementary calorimetric analysis of the sim-fuel samples showed that the presence of CsF and CsI in small quantities ( $\leq 1 \mathrm{~mol} \%)$ has almost no effect on the melting temperature of the MSR fuel.

\section{Outlook}

This paper showed a clear difference in volatility behavior of individual CsF and CsI chemical forms dissolved in the selected MSR fuel. Besides that, we further showed that exchange reaction between the CsI and fluoride matrix components takes place. To further explore the study and support these key findings, it would be essential to perform similar studies in the future on higher-order systems including mixtures of CsF and CsI and possibly of $\mathrm{LiI}$ and $\mathrm{ThI}_{4}$. Focusing on concentration variations would help in predicting the vaporization behavior typical for the concrete MSR concept. The experimental findings should be correlated with experimental data on the volatility behavior of these fission products from irradiated MSR fuel.

\section{Summary}

The present study showed that the volatility of Cs in the fluoride based MSR fuel can be 3 to 4 orders of magnitude lower compared to the elemental form.

Similarly, the volatility of I arising from CsI in the fluoride based MSR fuel can be about 2-3 orders of magnitude lower compared to the elemental form.

\section{Data availability}

The raw/processed data required to reproduce these findings cannot be shared at this time due to technical or time limitations.

\section{Conflicts of interest}

There are no conflicts to declare.

\section{Acknowledgements}

The authors would like to acknowledge the Analytical Service of JRC for the ICP-MS analysis of the selected samples. The HORIZON2020 EU-project SAMOFAR (grant agreement ID: 661891) is acknowledged for substantial financial support to perform the work.

\section{References}

1 H. Kleykamp, J. Nucl. Mater., 1985, 131, 221-246.

2 R. J. M. Konings, T. Wiss and O. Beneš, Predicting material release during a nuclear reactor accident, Nat. Mater., 2015, 14, 247-252.

3 E. Capelli, et al., Thermodynamic investigation of the LiF$\mathrm{ThF}_{4}$ system, J. Chem. Thermodyn., 2013, 58, 110-116.
4 D. Heuer, et al., Towards the thorium fuel cycle with molten salt fast reactors, Ann. Nucl. Energy, 2014, 64, 421-429.

5 HORIZON2020 EU-Project SAMOFAR, grant agreement ID: 661891.

6 C. Margheritis, G. Flor and C. Sinistri, Miscibility Gaps in Fused Salts, Z. Naturforschung A, 1973, 28A, 1329-1334.

7 E. Capelli, O. Beneš and R. J. M. Konings, Thermodynamics of soluble fission products cesium and iodine in the molten salt reactor, J. Nucl. Mater., 2018, 501, 238-252.

8 F.-Z. Roki, et al., Critical assessment of thermodynamic properties of CsI solid, liquid and gas phases, J. Chem. Thermodyn., 2014, 70, 46-72.

9 M. W. Chase Jr., NIST-JANAF Thermochemical Tables (Fourth Edition). Monograph No. 9, 1998, Journal of Physical and Chemical Reference Data.

10 C. W. Bale, E. Bélisle, P. Chartrand, S. A. Decterov, G. Eriksson, A. E. Gheribi, K. Hack, I. H. Jung, Y. B. Kang, J. Melançon, A. D. Pelton, S. Petersen, C. Robelin, J. Sangster, P. Spencer and M.-A. Van Ende, FactSage thermochemical software and databases - 2010-2016, Calphad, 2016, 54, 35-53.

11 E. Capelli, O. Beneš and R. J. M. Konings, Thermodynamic assessment of the LiF-ThF4-PuF3-UF4 system, J. Nucl. Mater., 2015, 462, 43-53.

12 N. Vozárová, et al., Thermodynamic determination and assessment of the CsF-ThF4 system, J. Chem. Thermodyn., 2017, 114, 71-82.

13 E. Capelli, et al., Determination of the thermodynamic activities of LiF and ThF4 in the LixTh1-xF4-3x liquid solution by Knudsen effusion mass spectrometry, Phys. Chem. Chem. Phys., 2015, 17, 30110-30118.

14 P. Souček, et al., Synthesis of UF4 and ThF4 by HF gas fluorination and re-determination of UF4 melting point, J. Fluorine Chem., 2017, 200, 3340.

$15 \mathrm{~J}$. Y. Colle, et al., Knudsen effusion mass spectrometry of nuclear materials: Applications and developments, ECS Trans., 2013, 46, 23-38.

16 R. Hultgren, et al., Selected values of the thermodynamic properties of the elements, American Society for Testing and Materials, 1973.

17 D. W. Bonnel, Program Sigmas, NIST, USA, 1990.

18 O. Beneš, et al., A DSC study of the NaNO3-KNO3 system using an innovative encapsulation technique, Thermochim. Acta, 2010, 509(1), 62-66.

19 G. W. H. Höhne, W. Hemminger and H.-J. Flammersheim, Differential Scanning Calorimetry, Springer Berlin, Heidelberg, 1996.

20 M. Eisenstadt, G. Rothberg and P. Kusch, Molecular composition of alkali fluoride vapors, J. Chem. Phys., 1958, 29(4), 797.

21 Y. Sekiguchi, et al., Fundamental study on the vaporization of cesium and iodine dissolved in LiF-NaF-KF molten salt, J. Nucl. Mater., 2019, 522, 136-143.

22 E. L. Compere, et al., Fission Product Behavior in the Molten Salt Reactor Experiment, Oak Ridge, TN, 1975. 